\title{
$\alpha_{\mathrm{k}}$
}

Research \& Methods E-ISSN 2544-0799

ISSN 1234-9224 Vol. 26 (1, 2017): 3-30

The Ohio State University

Columbus, Ohio, USA

Institute of Philosophy and Sociology

\section{Mixed Methods in Value Research: An Analysis of the Validity of the Russian Version of the Schwartz Value Survey (SVS) Using Cognitive Interviews, Multidimensional Scaling (MDS), and Confirmatory Factor Analysis (CFA)}

Maria Efremova

National Research University Higher School of Economics Moscow

Tatiana Panyusheva

National Research University Higher School of Economics Moscow

\section{Peter Schmidt}

University of Giessen and Humboldt Research Fellow of the Polish Foundation for basic Research

\section{Florian Zercher}

University of Giessen

The aim of this study is the validation of the Russian version of the Schwartz Value Survey (SVS) using qualitative (cognitive interviewing) and quantitative (multidimensional scaling, confirmatory factor analysis) methods. Specifically, this paper explores the issue of whether respondents interpret the values measured in the survey in the way intended by Shalom Schwartz. The analysis revealed problems with participants' understanding of the wording, which are due both to subtle differences in translation and to the cultural context. In addition, multidimensional scaling and confirmatory factor analysis were used to investigate whether the problems found in the qualitative analysis could also be detected by these quantitative methods. The findings of the qualitative analysis allowed a better understanding of the findings of the quantitative analysis and vice versa. However, the results differed considerably. In conclusion, several recommendations are given for use of such a mixed method approach.

Keywords: values; SVS; cognitive pretests; mixed methods; formal and construct validity; confirmatory factor analysis; multidimensional scaling; cross-loadings and error correlations. 


\section{Acknowledgements}

The research was conducted within the framework of the Basic Research Program at the National Research University Higher School of Economics (HSE) and supported within the framework of a subsidy granted to the HSE by the Government of the Russian Federation for the implementation of the Global Competitiveness Program.

\section{Note}

The order of authors as alphabetical expresses equal contribution of all four authors.

\section{INTRODUCTION}

Despite the widespread study of values in research, there are not many approaches that describe their contents and methods of measurement in detail (Aleman \& Woods 2016, Datler, Jagodzinski \& Schmidt, 2013; Inglehart, 1997; Kluckhohn \& Strodtbeck, 1961; Rokeach, 1973; Schwartz, 1992). One of the most widespread theories of values is the one postulated by Shalom Schwartz $(1992,1994)$ in the early 1990s. Over the years he has collected data in more than 70 countries around the world using the Schwartz Value Survey (SVS) inventory, and the dimensional structure postulated by the theory has been confirmed over and over again. A different version of the instrument, the Portrait Values Questionnaire (PVQ), has been repeatedly applied in recurring surveys such as the European Social Survey (ESS) and the World Value Survey (WVS). This measure contains fewer items and is more adequate for population surveys (Schmidt, Bamberg, Davidov, Hermann, \& Schwartz, 2007; Knoppen \& Saris, 2009). In addition, a new expanded version of the PVQ has been developed, tested in different countries, and recently published (PVQ5X; Schwartz et al., 2012). According to the theory of Schwartz, values can be studied at two levels of analysis: individual and cultural (Schwartz, 2014). Our work is devoted to the analysis of values at the individual level. For individuals, values represent the motivational goals that serve as guiding principles in their lives (Rokeach, 1973; Schwartz \& Bilsky, 1987). The first instrument for measuring individual values within the framework of this theory was the Schwartz Value Survey (Schwartz, 1992, 2005a). The SVS allows measurement of individual value priorities as well as of the relative importance of various separate values. In other words, the main object of analysis in the methodology proposed by Schwartz is the relative priority of a value in the respondent's individual hierarchy of values (see Figure 1; Schwartz, 2005a, 2006; Schwartz et al., 2012).

The SVS, based on Schwartz's theory, has gained in popularity among researchers since its introduction in the early 1990s. However, in a review of the literature, we were unable to find any analyses that utilized cognitive interviews together with quantitative techniques such as multidimensional scaling (MDS) or confirmatory factor analysis (CFA) to test the construct validity of the SVS. The use 
Figure 1. Theoretical model of relations among 10 motivational types of values.

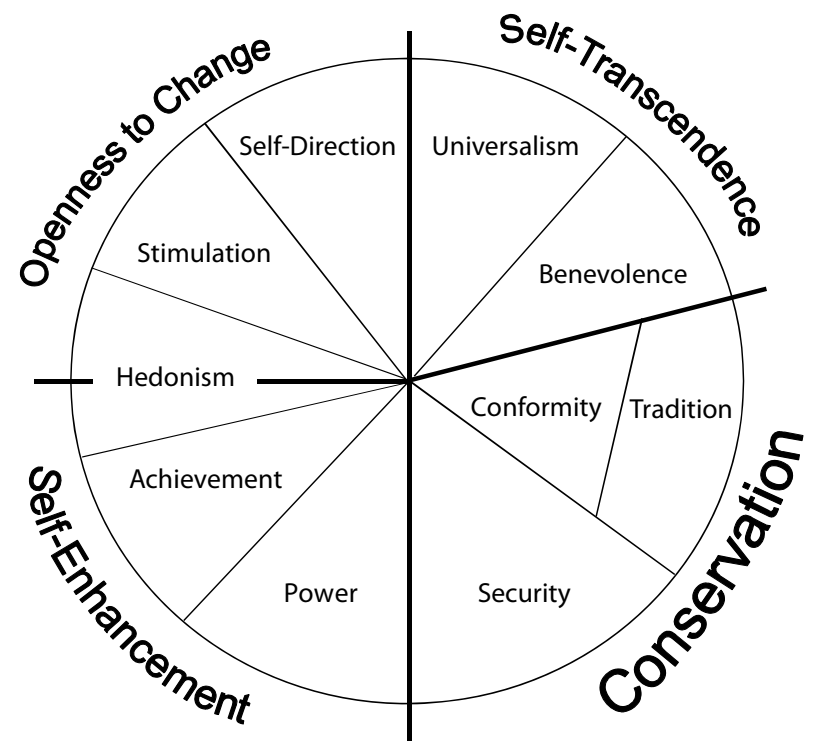

of both approaches seems to be important as Meitinger (2017) showed empirically that CFA may not be sufficient to find all weaknesses of items, and argued why cognitive interview techniques like probings are additionally necessary.

MDS (Schwartz, 1992, 1994, 2005a) and CFA (Schwartz \& Boehnke, 2004) were conducted to verify the equivalence of the meaning of the value items across cultures. Only those statements with an approximately equal meaning were included in the questionnaire. Schwartz reports that across 212 samples (national representative samples, teachers, students), alpha reliabilities of the 10 values average .68, ranging from .61 for tradition to .75 for universalism (Schwartz, 2005b). Using the combined approach of implementation of cognitive pretests as a qualitative method and of MDS and CFA as quantitative methods, we contribute to the mixed methods methodology approach (Boeije \& Willis; 2013, Castro, Kellison, Boyd, \& Kopak, 2010; Luyt, 2012; Robinson \& Mendelson, 2012; Petros, 2012) by specifically applying them to examine the validity of the Russian language version of the SVS.

In the present mixed methods contribution, our main research goals are:

(1) to understand and to identify the problematic survey items of the value instrument that are difficult to understand and to determine the causes of these problems (e.g., translation problems or discrepancies in understanding the content of values); 
(2) to determine how the problem of understanding the meaning of values influences the selection of scores by respondents (value ranking);

(3) to obtain, by means of cognitive interviews, a more detailed description of how the respondents understand all 57 values, which is useful for the description and interpretation of quantitative data derived from studies using the SVS;

(4) to use and compare both CFA and MDS to diagnose invalidity of items in terms of low loadings, cross-loadings, and residual correlations; and

(5) to compare the quantitative results of MDS and CFA with the qualitative results of cognitive interviews.

To summarize: using cognitive interviews, this study is the first attempt to investigate whether respondents understand the values they are asked to rank in the SVS while completing the survey. Understanding the meaning of the values in this case may be affected by subtle differences in translation and, of course, the cultural context. This paper also aims to determine how respondents rank the values (score selection strategy). Furthermore, we compare the results of two quantitative techniques (MDS and CFA) with the qualitative results, thus following a mixed methods approach that has not been applied until now.

Cognitive interviewing is the most adequate method for this kind of qualitative assessment of survey questions (Beatty \& Willis, 2007; Willis, 2005). This method is effective for detecting cognitive problems in questionnaires: problems involving the comprehension, recall, decision, or response processes necessary to answer the question adequately. Cognitive interviewing is likely to be an effective means for identifying potential problems before the problems are encountered repeatedly in the fielded survey. However, it can also be used to retrospectively explain findings of studies (Braun, Behr, \& Kaczmarek, 2012).

Latcheva (2011) used cognitive interviewing techniques together with both confirmatory factor analysis and exploratory factor analysis to analyze the meaning of items measuring nationalism and patriotism of the national identity module of the International Social Survey Program (ISSP; 1995, 2003). She was able to demonstrate that cognitive interviewing revealed problems of item formulation which remained, at least, partially undetected by factor analytic techniques. Schüßler and Schmidt (2008) reported similar findings for the concept of sexism.

It is also informative to compare the obtained qualitative data with the results of the quantitative data from our Russian sample $(\mathrm{N}=1,203)$ using both MDS and CFA, as these techniques are often used by researchers in the field of values research (Różycka-Tran, Khanh Ha, Cieciuch \& Schwartz 2017). Our research refers to different methods for testing equivalence of meaning and does not address all relevant aspects of methodological variability and errors in cross-cultural research including functional equivalence (Smith 2011, Wolf et al. 2016). 


\section{METHODS}

\subsection{Participants}

An appropriate sample size for the cognitive interviews was based on the analysis of the database of the International Scientific Educational Laboratory of SocioCultural Research, HSE (performed in 2010) (Lebedeva, Osipova, \& Cherkasova, 2013). Study 1 involved 1,203 respondents from three age groups (15-25 years, 26-39 years, and 40-74 years) with differing levels of education (Table 1). The data of three respondents were not included because of listwise deletion. Therefore, the final quota sample size was 1,200. In accordance with the socio-demographic characteristics of the quantitative research, a subsample was drawn with a similar percentage of respondents by sex, age, and education for the qualitative study using cognitive interviewing. This study involved 20 respondents (for a general discussion of sample size for cognitive interviews, see Blair, Conrad, Ackermann, \& Claxton, 2006); the characteristics of the sample are presented in Table 2. For the MDS Analysis we used a different sample comprising of 1723 respondents containing also the SVS (study 2).

Table 1 The Characteristics of the Sample from the Lab Survey in 2010

\begin{tabular}{lrrrrrr}
\hline Age & \multicolumn{2}{c}{$15-25$} & years & \multicolumn{2}{c}{ 26-39 years } & \multicolumn{2}{c}{$40-74$ years } \\
\hline Education level: & $\mathrm{M}$ & $\mathrm{F}$ & $\mathrm{M}$ & $\mathrm{F}$ & $\mathrm{M}$ & $\mathrm{F}$ \\
\cline { 2 - 8 } secondary education & 74 & 43 & 3 & 2 & 4 & 3 \\
college & 5 & 5 & 8 & 15 & 59 & 58 \\
not finished higher education & 179 & 296 & 15 & 13 & 16 & 15 \\
higher education, master's degree, PhD & 19 & 25 & 32 & 45 & 96 & 170 \\
Total & 277 & 369 & 58 & 75 & 175 & 246 \\
\hline
\end{tabular}

Note. $\mathrm{M}$ denotes male and $\mathrm{F}$ denotes female participants. Total $N=1,200$ after listwise deletion of 3 participants.

Table 2 The Characteristics of the Cognitive Interview Sample

\begin{tabular}{lcccccc}
\hline Age & \multicolumn{2}{c}{$15-25$ years } & \multicolumn{2}{c}{$26-39$ years } & \multicolumn{2}{c}{$40-74$ years } \\
\hline Education level: & $\mathrm{M}$ & $\mathrm{F}$ & $\mathrm{M}$ & $\mathrm{F}$ & $\mathrm{M}$ & $\mathrm{F}$ \\
\cline { 2 - 7 } $\begin{array}{l}\text { General secondary school } \\
\text { Specialized secondary school }\end{array}$ & 1 & 1 & - & - & - & - \\
$\begin{array}{l}\text { Some college } \\
\text { Undergraduate/postgraduate/ }\end{array}$ & 3 & 4 & - & - & - & - \\
doctorate degree & 1 & 1 & 1 & 1 & 2 & 3 \\
Total & 5 & 6 & 1 & 1 & 3 & 4 \\
\hline
\end{tabular}

Note. $\mathrm{M}$ denotes male and $\mathrm{F}$ denotes female participants. Total $N=20$ participants. 


\subsection{Research Methods}

In our study, we used a Russian-language version of the SVS to study Schwartz's values at the individual level. The validation of the questionnaire to assess the values was conducted using a Translation, Reviewing and Adjudication (TRAPD) procedure (Harkness, van de Vijfer, Mohler 2010): double translation of the statements was performed and the translations were compared. Schwartz then constructed the final version of the questionnaire in Russian and agreed it (Lebedeva, 2001). This work was done within the project "Continuity and Variability of basic values in Russian culture" and also as a part of the project "Socio-cultural factors of economic development". The description of the complete version of the questionnaire and the reliabilities are reported in the book "Kul tura kak faktor obwestvennogo progressa" (Lebedeva \& Tatarko 2009). The reliabilities of the scales (Cronbach`s Alpha) were as follows and are placed after the different value constructs: Power(.70), Conformity(.61), Benevolence(.68), Security(.64), Tradition(.66), Universalism(.66), SelfDirection(.66), Stimulation(.70), Hedonism(.52), Achievement(.65).

One of the main goals of cognitive interviewing consists of determination of the extent to which the meaning of the questions as written by the researcher is consistent with the way respondents interpret them. This is accomplished by testing and evaluating the quality of the question with the following special cognitive techniques: "think-aloud", paraphrasing, sorting, confidence judgment, and verbal probing. A more detailed description of the methods, the theoretical foundations, applied techniques, requirements, data analysis, and procedures for sample size can be found in the relevant literature (e.g., Blair et al., 2006; Hak, van der Veer, \& Jansen, 2008; Prüfer, 2011; Rogozin, 2002; Tourangeau, 1984; Willis, 2005).

Specifically, the present study employed the following cognitive interviewing techniques:

1) Think-aloud:

- As the subjects responded to each survey question they were asked to verbalize what they were thinking. In cases where the participants did not provide comments to a particular survey item, the researcher did not try to elicit comments, since the procedure of completing the survey had to be as authentic as possible. If the respondent did not agree with the explanation of a word or a phrase, he/ she was immediately asked to try to formulate their version of understanding or interpretation.

We chose this technique because "think aloud" provides us with useful information about how the participants understand the questions they are asked, what problems occurred in comprehension, and the possible reasons for this. In 
addition, the subject's verbalization is guided only minimally, and respondents may provide valuable information that is unanticipated by the interviewer.

2) Verbal probing:

- Subjects are asked questions to further probe their understanding of the research question as a whole or the individual terms (comprehension/interpretation probe). Examples of this include: "What does the term 'devout' mean to you?", "How do you interpret the phrase "world of beauty?", "Does your understanding correspond to the decoding in parentheses or not?", and "Are all the main points mentioned in the interpretation?"

This technique was also important for us because many of the values in the SVS are described using concepts or word combinations whose meaning can be understood in different ways.

Category selection probing has the goal of determining why respondents choose a particular category of response. However, it must be pointed out that during the actual interviews in the course of this study, there was almost no need for category selection probing since all the information related to this could be obtained from the think-aloud protocols.

Of the two general approaches to probing, that is, concurrent (after each item) or retrospective (after completing the entire survey), we decided to use concurrent probing because the SVS questionnaire was quite long, and concurrent probing asks for information that is still fresh in the subject's mind at the time of the probing. Retrospective probing, in our case, would have the inherent risk that when asked about it later subjects may no longer remember what they were thinking as they answered a question.

When analyzing cognitive interview data, both the issues identified by individual participants and the dominant "prevailing" tendencies that manifest themselves during interviews are regarded as problems. In this paper we focus on the description of the dominant trends in the responses of the subjects, as our task is to identify those problems in the survey that may be more likely to affect the quality of the data. For the sake of brevity, we will not present the detailed results of the respondents' understanding of each survey item in the form of detailed descriptions of all the values. These results can be found in the Appendix.

\subsection{The Procedure for the Study}

Before conducting interviews, we obtained the consent of the participants to recording of the interviews by audiotape, and guaranteed confidentiality assuring them that the use of the interview transcript was for research purposes only. Respondents were also informed that the purpose of the conversation was to validate a value survey. Next, the interview procedure was presented in detail to each participant. 
First, instructions for completing the questionnaire were given, and the rules for filling out the forms were clarified. Second, participants were told that they should try to verbalize their thoughts (i.e. thinking aloud) while answering the questions in both parts of the questionnaire. Third, they were informed that the researcher may ask additional questions (i.e. probing) for each item of the survey. Fourth, after completing the questionnaire, respondents were given time and space to leave any additional comments and opinions about the survey that they might have, for example, regarding the clarity and difficulty of items.

\section{QUALITATIVE RESULTS}

Our study identified the problems that the survey questions posed for respondents in terms of their correct understanding and evaluation of them. This is partially related to the translation of the survey into Russian and partially related to the value content and value decoding interpretation by the Russian-speaking respondents.

The problems identified in understanding of the questionnaire items influenced respondents' selection of the most fitting response alternative. In cases in which a respondent's interpretation did not coincide with the intended content, participants either rated their own understanding (with high scores) or evaluated the given statement (with low scores) or assigned two different scores: one for their own interpretation and a separate one for the decoding provided in the survey. In instances where the name and/or the definition of the value were not clear to the respondents (e.g., rarely used words) or it where it was unclear what was meant by a particular value, the participants acted in the following ways:

- They rated their "misunderstanding";

- In some cases if the name of the value was unclear but the decoding included in parentheses was more understandable a score was given only to the description provided in parentheses;

- Sometimes respondents provided a rating based on the relationship they ascertained between the value that was not very clear and another item from the list of values; this strategy influenced their selection of scores.

Hence, it is clear that the problem of understanding the language describing the values affects participants' processes of completing the survey and selecting scores for individual questions. Thus, to be able to carry out a quantitative analysis of the scores obtained through survey completion, we need to examine which of the survey items are the most problematic for the respondents in terms of understanding, and perhaps make some adjustments or take into account the difficulties while interpreting results and conducting further research. 


\subsection{Understanding the SVS Value Names and Definitions: Results}

As a criterion for indicating that the understanding of a survey item was problematic for the subjects, we looked at situations where $50 \%$ (or more) of the sample expressed disagreement with the wording of a value (see Table 3). Since there is no clear cut-off point provided in the literature on cognitive interviews (Beatty \& Willis, 2007; Willis, 2005) we selected 50\%, due to our small sample size.

Table 3 The SVS Values and the Respondents' Difficulties in Understanding Them and Results of the MDS and Simultaneous CFA Analyses

\begin{tabular}{|c|c|c|c|c|}
\hline 10 broad values & 1 & 2 & 3 & 4 \\
\hline $\begin{array}{l}\text { Security: } \\
\text { - social order } \\
\text { - reciprocation of favors } \\
\text { - national security } \\
\text { - family security } \\
\text { - clean }\end{array}$ & $\begin{array}{l}\text { high } \\
\text { high } \\
\text { low } \\
\text { low } \\
\text { low }\end{array}$ & & $\begin{array}{l}\mathrm{R} \\
0 \\
0\end{array}$ & $\begin{array}{l}\mathrm{C} \\
\mathrm{NC} \\
\mathrm{NC} \\
\mathrm{NC} \\
\mathrm{NC}\end{array}$ \\
\hline $\begin{array}{l}\text { Conformity: } \\
\text { - obedient } \\
\text { - politeness } \\
\text { - self-discipline } \\
\text { - honoring parents and elders }\end{array}$ & $\begin{array}{l}\text { high } \\
\text { low } \\
\text { low } \\
\text { low }\end{array}$ & & 0 & C \\
\hline $\begin{array}{l}\text { Tradition: } \\
\text { - humble } \\
\text { - accepting my portion in life } \\
\text { - devout } \\
\text { - respect for tradition } \\
\text { - moderate }\end{array}$ & $\begin{array}{l}\text { high } \\
\text { high } \\
\text { high } \\
\text { low } \\
\text { low }\end{array}$ & 1 & * & $\begin{array}{l}\mathrm{NC} \\
\mathrm{C} \\
\mathrm{NC} \\
\mathrm{NC}\end{array}$ \\
\hline $\begin{array}{l}\text { Benevolence: } \\
\text { - responsible } \\
\text { - honest } \\
\text { - loyal } \\
\text { - helpful } \\
\text { - forgiving }\end{array}$ & $\begin{array}{l}\text { high } \\
\text { low } \\
\text { low } \\
\text { low } \\
\text { low }\end{array}$ & & & $\mathrm{NC}$ \\
\hline $\begin{array}{l}\text { Universalism: } \\
\text { - unity with nature } \\
\text { - wisdom } \\
\text { - social justice } \\
\text { - broadminded } \\
\text { - equality } \\
\text { - a world at peace } \\
\text { - a world of beauty } \\
\text { - protecting the environment }\end{array}$ & $\begin{array}{l}\text { high } \\
\text { high } \\
\text { high } \\
\text { high } \\
\text { low } \\
\text { low } \\
\text { low } \\
\text { low }\end{array}$ & & $\begin{array}{c}0 \\
\\
0 \\
(+) \\
\mathrm{R} \\
\mathrm{OR}\end{array}$ & $\begin{array}{c}\mathrm{NC} \\
\mathrm{C} \\
\mathrm{NC} \\
\mathrm{C} \\
\mathrm{NC} \\
\mathrm{NC} \\
\mathrm{NC}\end{array}$ \\
\hline
\end{tabular}


Self-Direction:

- creativity

- freedom

- independent

- curious

- choosing own goals

high

low

low

low

low

$\mathrm{R} \quad \mathrm{C}$

Stimulation:

- daring

- an exciting life

high

- a varied life

low

low

$\mathrm{NC}$

$\begin{array}{ll}0 & \mathrm{NC} \\ 0 & \mathrm{NC}\end{array}$

Hedonism:

- pleasure

- enjoying life

high

high

- self-indulgent

low

$\mathrm{NC}$

Achievement:

- ambitious

- influential

high

low

- capable

- successful

low

low 0 NC

Power:

- authority

high NC

- social power

low

- wealth

- preserving my public image

low

low

$\mathrm{NC}$

$\mathrm{NC}$

NC

Note. $\mathrm{R}=$ significant error correlation; $(+)=$ factor loading under $0.4 ; 0=$ significant cross-loading; ${ }^{*}=$ significant cross-loading and low factor loading; I = Item belongs to another domain of values; C = Consistency; NC

= No Consistency.

Column designations:

1: The degree of the difficulty in understanding High (understanding was problematic for half or more than half of the respondents) Low (difficulty in understanding in less than half of the respondents).

2: Items that were deviant in quantitative analysis (MDS) and were also identified as deviant in the qualitative analysis.

3: Items that are different in quantitative CFA, error correlations, cross-loadings, and low factor loadings.

4: Items that were deviant in quantitative analysis (CFA) and were also identified as deviant in the qualitative analysis.

\subsection{Values of Conservation}

Security. The majority of the respondents offered their own definition of the value item "social order (stability of society)"; however, this value was understood in different ways, which is reflected in the fact that the participants chose very differing criteria. Predominating were the criteria of an "objective" character, when social order was interpreted as the existence and implementation of laws and norms in society as well as an absence of disorder and crime. Perhaps this diversity of opinion on social order is due to the fact that this topic is rather painful in Russian society and sometimes provokes strong emotional reactions in people. 
Thus, a more detailed wording in the decoding would contribute to the better and more unified understanding of this value.

Specifically, the value item "reciprocation of favors (avoidance of indebtedness)" was not understood as intended by the SVS: $65 \%$ of the participants expressed their understanding of the given value in a way that strongly differed from the survey definition. For the Russian respondents, the value did not represent avoidance of indebtedness but rather willingness to give something to other people without expecting anything in return, providing mutual support and mutual assistance, or just a desire to help others. In addition, it is important to note that the phrase "reciprocation of favors" was difficult to understand.

Conformity. The value item "obedient (fulfilling obligations; being aware of one's duty)" was understood by most respondents (70\%) in a different way, and the wording provided was perceived as characteristic of a responsible person. An obedient man was understood by participants as a person unquestioningly obeying superiors, listening to someone, complying with the rules, obliging, and diligent. The problems reported by respondents were related to the title of the value. The word "obedient" was interpreted with a negative connotation, which prevented respondents from assigning a higher score to this value.

Tradition. More than half of the participants did not agree with the decoding provided for the value item "humble (temperate, preferring to stay in the background)", particularly with the explanation "preferring to stay in the background". In general, the definition provided provoked, in their view, a negative attitude toward this value, whereas in fact "humble" itself is perceived in a positive way. Understanding of "humble" by the participants differed from the meaning specified in the decoding, and at the same time, the descriptions provided by the participants were diverse. In the following section we describe the responses in cognitive interviews: (1) a shy person who avoids public appearance, reserved; (2) a person that does something not with the aim of being highly regarded by others; understanding of "humble" as courtesy and tact; (3) a person realistically assessing themselves, their abilities, knows their own worth, takes life as it is, a person without unrealistic demands, a temperate individual who knows how to behave appropriately in different situations.

For the value item "accepting my lot in life (taking life as it is)", about half of all participants expressed a negative attitude toward its very name - accepting my lot in life. This wording was regarded as pretentious and indicative of a person's passivity, viewing oneself as a victim, complaining about one's life. At the same time, the phrase "taking life as it is" was consistent with the respondents' notion of the value. For them, it meant a realistic view of life, satisfaction with one's life and, at the same time, the ability to change it, to strive for something. 
With regard to the value item "devout (observing religious beliefs)" it is important to note that the word devout is unfamiliar to people, and they often do not know its exact meaning. Some of the participants perceived the word devout a little differently than intended, that is, only rarely associated, as was suggested in the decoding, with religion. They interpreted the word more broadly in the sense of following norms, rules of morality, principles, and beliefs, even as wisdom and understanding of life. Thus, if the main emphasis in this item is on the observance of religious beliefs, then the term "believer" or something analogous would be more understandable for people; however, if a broader context is meant, it is desirable to find a word more comprehensible and common to refer to this value.

\subsection{Values of Self-Transcendence}

Benevolence. For the value item "responsible (trustworthy, reliable)", many respondents felt that part of the definition (i.e. trustworthy) does not quite characterize a responsible person. Most participants viewed a responsible person as a person that can be relied upon, a person who keeps his/her word, who fulfills obligations, and takes responsibility for the consequences of their actions.

There were no reported problems understanding the value item "honest". However, even though most respondents agreed with the definitions for the other three value items, "loyal", "helpful", and "forgiving", in describing their understanding of their meanings most of the participants provided a broader interpretation of these items. For example, the value item "loyal (faithful to his friends, group)" is understood not only as being loyal to friends and the group, but also being true to one's family, word, and convictions. The value "helpful", from the perspective of the participants, was not only limited to the sense of benefiting others, and included caring for others, protecting them, and willingness to make compromises. In connection with the value item "forgiving (ready to forgive the mistakes of others)", respondents expressed two recurring ideas: A person should not only be ready, but also be able, to forgive the mistakes of others; and importantly, they should recognize their own mistakes.

Universalism. In the value item "unity with nature (harmony with it)", the part of the definition about fitting into nature seemed to be rather controversial and caused confusion or outright disagreement in a rather large number of the respondents. The most common option was to understand "unity with nature" as a respectful and caring attitude toward nature and regular interaction with it (outdoor recreation, etc.).

"Wisdom (a mature understanding of life)": more than half of the subjects did not agree with the definition of wisdom as a mature understanding of life 
because, in addition to not clarifying the meaning of the word, it actually made it more confusing for them. Although often associated with age, the respondents themselves did not relate to the notion of age while interpreting "wisdom", assuming, for example, that children may also be wise, and so on. Respondents described wisdom as an accumulation of life experience, the ability to understand the position of other people and to look at the situation from different points of view, the ability to see what others do not see, the ability to admit mistakes and to forgive the mistakes of others, and the ability to foresee the consequences of their actions.

Several major trends of understanding of the value item "social justice (elimination of injustice, care for the weak)" were identified. The most common trend among the respondents (14 people, $70 \%$ ) consisted of considering social justice in terms of equal rights and equal opportunities for all people; when based on merit and effort, a person can achieve something, and the rules in the community are to be equally complied with by all. For some respondents, in addition, "care for the weak" was also included in the concept of social justice, but for others it was not. In contrast, the second, less represented approach (four people, 20\%) regarded social justice as primarily a concern for the weak and the needy. It is worth mentioning that $25 \%$ of the respondents (five people) noted that, for them, the value "social justice" intersected with the value "equality"; some even regarded these to be the same thing and felt that one of these values could be removed from the questionnaire.

Seventy percent of the participants did not agree with the wording of the value item "broadminded (tolerant of different ideas and beliefs)". The definition of "tolerant of different ideas and beliefs" was interpreted as a description of a tolerant, patient person. The term "broadminded" was understood by the participants as an attribute expressing openness to look at something from different points of view and listen to other people's opinions. This is also an individual who has vast knowledge in various fields, is open-minded, and able to go beyond the established limits to find new solutions.

\subsection{Openness to Change Values}

Self-Direction. For the value item "creativity (uniqueness, imagination)", most respondents $(65 \%)$ did not agree with the description of creativity through uniqueness. Creativity was perceived by them, first, as a process of creating something; self-expression; embodiment of some thoughts; creativity may manifest itself not only in art but in any other thing as well (in a game, in creating a garden, etc.). Imagination, in their understanding, was also included in the concept of creativity. 
Stimulation. Regarding the "courageous (looking for adventure, not afraid to take risks)" value item, more than half of the participants agreed with only half of its definition. "Not afraid to take risks" disclosed to them the meaning of this item, while "looking for adventure" seemed quite inappropriate. A courageous person, in the view of respondents, can take risks, if necessary, for the sake of something important (friends, saving someone's life, defending their beliefs), and he/she will overcome difficulties when they arise.

The meaning of the value items "an exciting life" and "a varied life" was clear to the respondents. It is important to emphasize that, despite the overall absence of interpretation problems with each of these two values, $65 \%$ of participants believed that the values "an exciting life" and "a varied life" constituted the same thing and did not see any difference between them.

\subsection{Self-Enhancement Values}

Hedonism. For the value item "pleasure (satisfaction of desires) ", by the term "pleasure", more than half of all participants understood a wider range of things than was intended in the definition. In their view, a person can get pleasure in life not only from the satisfaction of desires (primary needs), but from many different things: work, hobbies, etc. That is, pleasure, for many, even involves primarily spiritual satisfaction.

For the value "enjoying life (enjoys food, sex, entertainment, etc.)", $65 \%$ of participants did not perceive enjoying life in the way intended by its definition, but, as in the case of the value "fun", more broadly, as experiencing joy from totally different things: activity, work, family, sharing joy with another person, communication, friendship, reading, etc.

Achievement. In the value item "ambitious (working hard to succeed) ", more than half of the respondents believed that an ambitious person does not necessarily work hard. Such a person strives for success, for social recognition, and is willing to get results at any cost; for them, this defines an ambitious person, a careerist, and so on. It is also important to note that some people (in this case, two) had difficulty understanding the word "ambitious" and were not sure that they understood its precise meaning.

In the Dictionary of Modern Russian Language, "ambitious" means tending to ambition. Ambition is understood as a desire for fame, honor, wanting an honorable position (Ozhegov, 2010).

Power. For the value item "authority (the right to lead and give directions)", most of the participants (75\%) completely disagreed with the definition of "authority" as the right to lead and give orders, considering that rather as a characteristic 
of power. Authority, in the understanding of the respondents, is the respect and recognition received from others; recognition of the competence of a person in any area; informal leadership, when people appreciate the opinions of a particular person and are drawn to this person by some of his/her personal qualities.

To summarize, utilizing the cognitive interview technique, the qualitative study identified the survey items which caused difficulty in understanding (or interpretations that are different from the given definitions) for a large number of respondents, thus affecting their ratings on these values. The advantages of these findings are twofold: First, based on the problems identified, with the consent of the author (S. Schwartz), adjustments can be made to the Russian version of the survey, and second, when applying the current version of the Russian-language SVS, the implications of these item comprehension discrepancies can be taken into account. In addition, the results of our study revealed not only comprehension problems related to the individual items of the value survey, but also more common problems that affected the completion of the survey by respondents. Specifically, they perceived the items as being from different levels of generality. Therefore, it was difficult for them to make a comparison.

Cognitive interviews with native Russian speakers provided us with results which reveal some of the underlying problems of understanding the names and the decodings of the 57 items in the Russian version of the SVS. However, it appears that the problems uncovered in the process of filling out the survey may relate not only to difficulties in understanding the description of specific values, but also to causes of a more general nature. The main results of the cognitive interviews can specifically be summarized as:

- It is difficult to evaluate some of the items because they are not perceived as values (it is difficult for respondents to perceive them as values or they are perceived as needs) (2 people).

- Some values are regarded as more "global" and some as more "personal, internal" in nature, which also makes their evaluation difficult (2 people).

- Some values are perceived as more "scientific" and some as more "ordinary" in nature (1 person).

- Values do not correlate with each other in terms of their levels (3 people).

These problems were stated by 8 of the 20 respondents, thus representing $40 \%$ of the cognitive interview participants. Related to this problem - the difficulty of correlating the items - is the risk that respondents will not evaluate each item according to its significance in a series of other items but rather as a separate value. Or respondents may assign lower scores to some values, as some participants mentioned. This risk is increased by the fact that the SVS is used in studies as a selfcompletion survey, that is, it is filled in without the presence of an interviewer. 
While completing the survey, the respondents had questions about the instructions. First, the question came up of whether the respondents should rate how they would like things to be (i.e., their ideal) or how things are actually arranged in their lives (i.e., their reality). Separate studies have shown that, on average, respondents answer items in terms of realistic ideals, which actually falls between these two. However, for some respondents in our study it was a genuine problem, and they asked the interviewer about this. Others did not discuss this problem, but it was evident during their "thinking aloud" vocalizations that they answered sometimes in accordance with one point of view and sometimes with the other.

Second, the question was raised about whether the respondents evaluate themselves or others when responding to the items. Thus, either the person values being "as such" and values "something", or it is important to him that other people are "as such" and value "something. "This problem points to a serious issue that was identified relating to the fact that the respondents did not know what to rate at each point. The first aspect deals with the question of rating the extent to which this or that value is currently, in fact, implemented in their lives or the way they would like it to be implemented. The second aspect questions whether they should evaluate themselves or others, by either considering the importance of each value as a quality important in itself or as a quality that the respondent wants to see in others. In fact, the second aspect of this problem occurs much more frequently than the first. Some of the participants raised these issues directly, while others selected their rating one way or the other without discussing this with the interviewer. As a result, the content behind the scores that were given on various grounds will vary widely, and it would be incorrect to compare these data with each other. Of course, it is important for any survey that the participants clearly understand what they are required to evaluate. Perhaps this problem can be solved through a more precise formulation of these aspects in the instructions. The qualitative data presented here has clearly revealed problems in item formulation in the Russian-language SVS, which leads to different levels of understanding in survey participants. Now we turn to the quantitative analyses of the SVS, which are presented in the next section.

\section{QUANTITATIVE RESULTS}

\subsection{What does Multidimensional Scaling Tell Us?}

The results of the qualitative analysis can be now compared with the results of the MDS analysis. The SVS has been repeatedly used in studies on large samples in Russia, as is the case for the data evaluated in the present study (see Figure 2). 
Figure 2. Location of values according to the design matrix in two-dimensional multidimensional scaling (Bilsky et al., 2011). UN = universalism; $\mathrm{BE}=$ benevolence; TR = tradition; $\mathrm{CO}=$ conformity; $\mathrm{SC}=$ security; $\mathrm{PO}=$ power; $\mathrm{AC}=$ achievement; $\mathrm{HE}=$ hedonism; $\mathrm{ST}=$ stimulation; $\mathrm{SD}=$ self-direction.

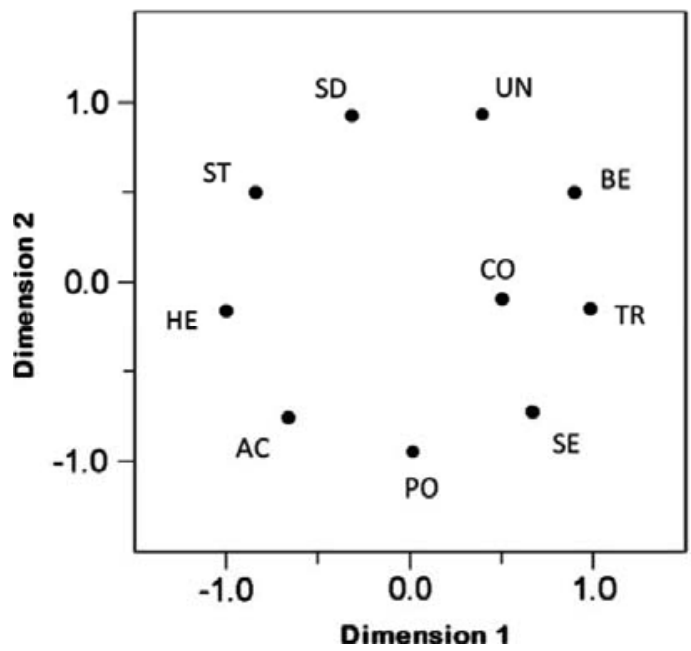

Data for the analyses were collected from study 2 with representative samples of 1,723 participants from the Central District of Russia including Moscow, and from the North Caucasian Federal District. The participants were recruited using the snowball sampling technique. The completion of the questionnaire took on average 25 minutes.

The MDS method revealed the layout peculiarities of several values that differ from their usual positioning in Schwartz's (1992, 1994) model. Perhaps some of these can be easily understood in the light of the qualitative data illustrating how respondents understand certain values.

Data analysis. The MDS program in SPSS 19.0, PROXSCAL (with z-transformation) was used for the structural analysis of the valued data. A more detailed description of the MDS method can be found in Borg and Groenen (1997).

MDS is used for the visual assessment of the value structure and shows the relations among items based on similarity in how respondents rate them (correlations). This technique represents the values as points in a multidimensional space such that the distances between the points reflect the empirical relations among values as measured by the correlations between their importance ratings. The greater the conceptual similarity between two values, the more related they should be empirically and, hence, the closer their locations should be in the multidimensional space. 
Schwartz's $(1992,1994)$ theoretical model implies a circular, quasi-circumplex in which each orientation is close to (i.e. correlates positively with) those with which it is compatible and distant from (i.e. correlates negatively with) those with which it conflicts. The a priori assignment of items to values guides the partitioning of the maps.

Figure 1 presents the theorized quasi-circumplex model (Cieciuch \& Schwartz, 2012). The 10 values are represented in nine sectors, with one sector divided into inner (conformity) and outer (tradition) subsectors. Following Bilsky, Janik, and Schwartz (2011), Schwartz spaced the nine values equally around the circle because the theory specifies no particular spacing. Each of the nine sectors covers an angle of 40 degrees, enabling the calculation of theory-based coordinates for the items that index each value.

MDS has been used to analyze SVS data (Fontaine, Poortinga, Delbeke, \& Schwartz, 2008; Schwartz 1994, 2006), as has CFA (Schwartz \& Boehnke, 2004). These studies all lead to the following conclusions: MDS analyses generally confirm the circular structure. In addition, visual inspection of the two-dimensional MDS space usually suggests that 10 values can be distinguished.

Figure 3. Multidimensional scaling of the Russian SVS items. $N=1,203$. Fit Indices: Stress 1.37, DAF .86, TCC .93, poor fit. SDT = self-direction, thoughts; UNN/T = universalism nature/tolerance; $\mathrm{TR}=$ tradition; $\mathrm{BE}=$ benevolence; UNC = universalism care; $\mathrm{CO}=$ conformity; $\mathrm{SE}=$ security; $\mathrm{AC}=$ achievement; SDA = self-direction, actions; $\mathrm{HE}=$ hedonism; $\mathrm{PO}=$ power; $\mathrm{ST}=$ stimulation.

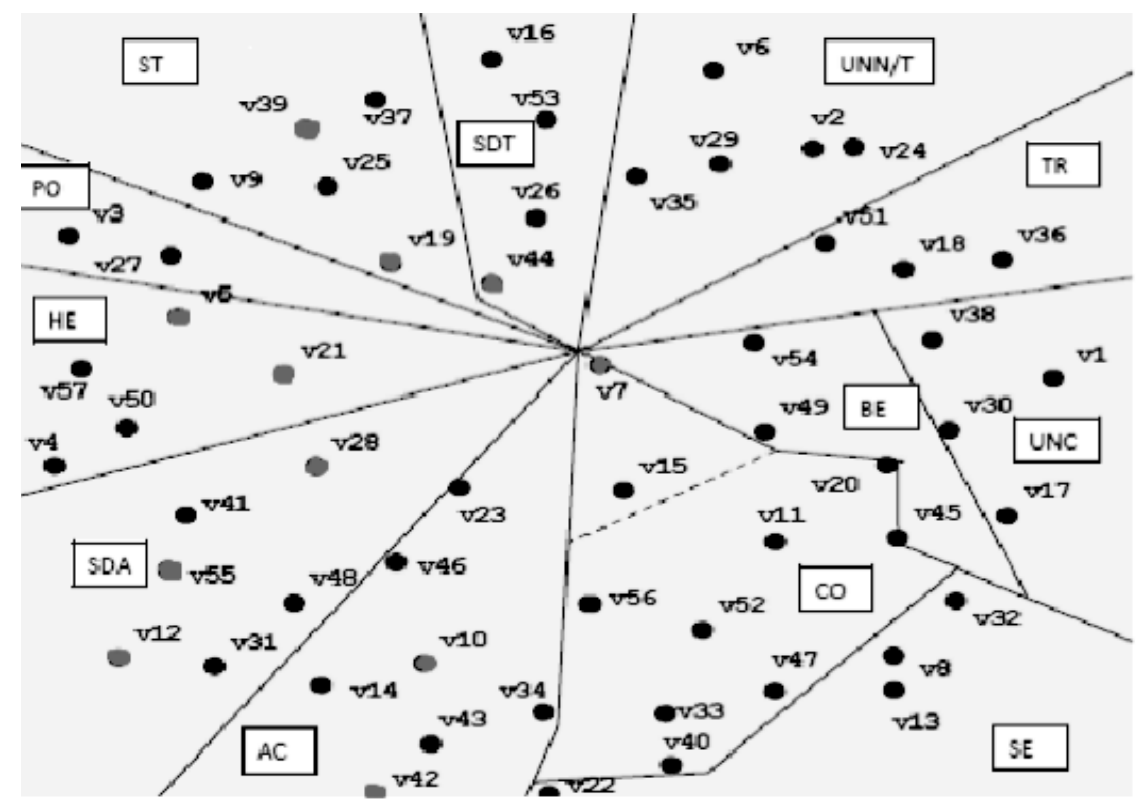


Figure 3 presents a two-dimensional projection of the value items from the SVS (for the Russian sample, 2010). First, the data obtained revealed that some of the points $(5,7,10,12,19,21,28,39,42,44,55)$ were not located in their usual places in the model. Interestingly, four of them, according to our data, were included in the list of values that were interpreted by respondents in a way that differed from the intent of the survey. Specifically, these were: "sense of belonging" (v7), "accepting one's lot in life" (v44), "mature love" (v19), and "meaning in life" (v10). For example, even though the value "accepting one's lot in life" is usually among the values in the group "Tradition", in this case, it was closer to the values in the group "Self-Regulation" (together with the values "inquisitive" and "creativity "). Here, it should be mentioned that the interpretation of the value "accepting one's lot in life" by the respondents is, in fact, closer to "Self-Regulation", because the respondents perceived as a value its decoding (accept life as it is) and not its name, and understood it to not be a passive acceptance of one's life, in this sense close to the values of "Tradition", but as a realistic view of life, satisfaction with their lives and, at the same time, the ability to change it, and to strive for something.

The other two values - "freedom" (v5) and "private life" (v21) - were unexpectedly found to be close to the values of "Hedonism". On the one hand, these two values did not generally pose problems of understanding to the participants in the present research. On the other hand, it is important to note that the values that belong to "Hedonism" were interpreted in a way quite different from the one specified in the survey. Thus, pleasure and enjoying life were considered by the participants not as meeting primary needs, but in a much broader sense as getting pleasure and joy from a large variety of things: communication, family, friendship, work, hobbies, etc. That is, for a large number of respondents, Hedonism, first and foremost, included spiritual satisfaction. In this sense, we can see that both "freedom" and "private life" are close to this value group. "Private life" was interpreted not only as the right to one's own space, but as a wider range of rights: the right to one's own space and time, the right to non-interference from other people, the right guaranteeing the opportunity to do what one wants. That is, a person is free in his/her choice of what to devote his/her time to, from what to receive joy in life. This interpretation of private life is close to the understanding of the value "freedom".

Another pair of values-"wealth" (v12) and "successful" (v55)-was not located among the values of "Power" and "Achievement", but close to the values of "SelfRegulation", namely, near the points "independent" and "successful". In this case, we can note the following ideas: First, in interpreting the value "independent", some of the participants mentioned the importance of aspects such as material or financial independence (20\%). Moreover, items such as "successful", that is, a person who achieved something in life and determining life goals, and interpreted 
by most respondents as the ability to independently set and achieve their goals, appeared to be close to each other in their content.

Examining the location of the item "meaning in life" (v10) we notice that it unexpectedly appeared among the values of the group "Achievement". However, according to many respondents (45\%), the decoding of "meaning in life" through the phrase "having goals in life" was incorrect, and they offered their own versions. In this situation, the respondents chose what to evaluate - either their understanding of the value or the description given - often choosing the latter. Then, if we consider "meaning in life" through the given definition as having goals in life, it is not surprising that this item appeared in the block "Achievement" next to the values "ambitious" and "capable", since these sub-items are also associated with the ability to successfully achieve one's goals. Thus, this analysis showed that a different interpretation of a value by respondents affects its location in the structure of values. As a consequence of the results of the MDS analysis we deleted 11 value items in the CFA analysis in section 4.2. which used only the subset of 46 items. The deleted eleven items were: "sense of belonging", "meaning in life", "mature love", "inner harmony", "a spiritual life", "self respect", "social recognition", "true friendship", "healthy", "intelligent" and "privacy".

\subsection{What Does Confirmatory Factor Analysis Tell Us?}

As a data-base for the simultaneous confirmatory factor analysis (SCFA) we used the data from study 1 with 1200 respondents. We used SCFA (maximum likelihood estimation) to test the same measurement model (see also Schwartz \& Boehnke, 2004; Beierlein, Davidov, Schmidt, Schwartz \& Rammstedt, 2012) as in MDS but with a reduced number of 46 items. The path diagram in Figure 4 presents a visualization of the tested measurement model. We assumed, as in MDS, that all 10 factors are correlated, but do not show this relationship in the figure to make the diagram easy to read. We did not allow for error correlations or cross-loadings in the model (see Brown, 2015).

According to the global fit measures, the fit of the model was poor (Brown, 2015). The comparative fit index (CFI) had a value of 0.744 , the chi-square/degrees of freedom ratio $\left(\mathrm{chi}^{2} / \mathrm{df}\right)$ was 5.74 , the standardized root mean square residual (SRMR) was 0.070 , the root mean square error of approximation (RMSEA) was 0.063 , and the probability of close fit (pclose) was 0 . The reasons for this poor fit were the large numbers of cross-loadings and error correlations. In addition, we have to take into account the amount of formal validity of the items represented by the factor loadings, although they do not influence the global fit of the model (see Brown, 2015). We used, as a criterion, a standardized factor loading of at least 0.4. In Table 3, the results of the cognitive interviews, MDS, and the simultaneous 
Figure 4. Simultaneous confirmatory factor model for the SVS in notation of AMOS.

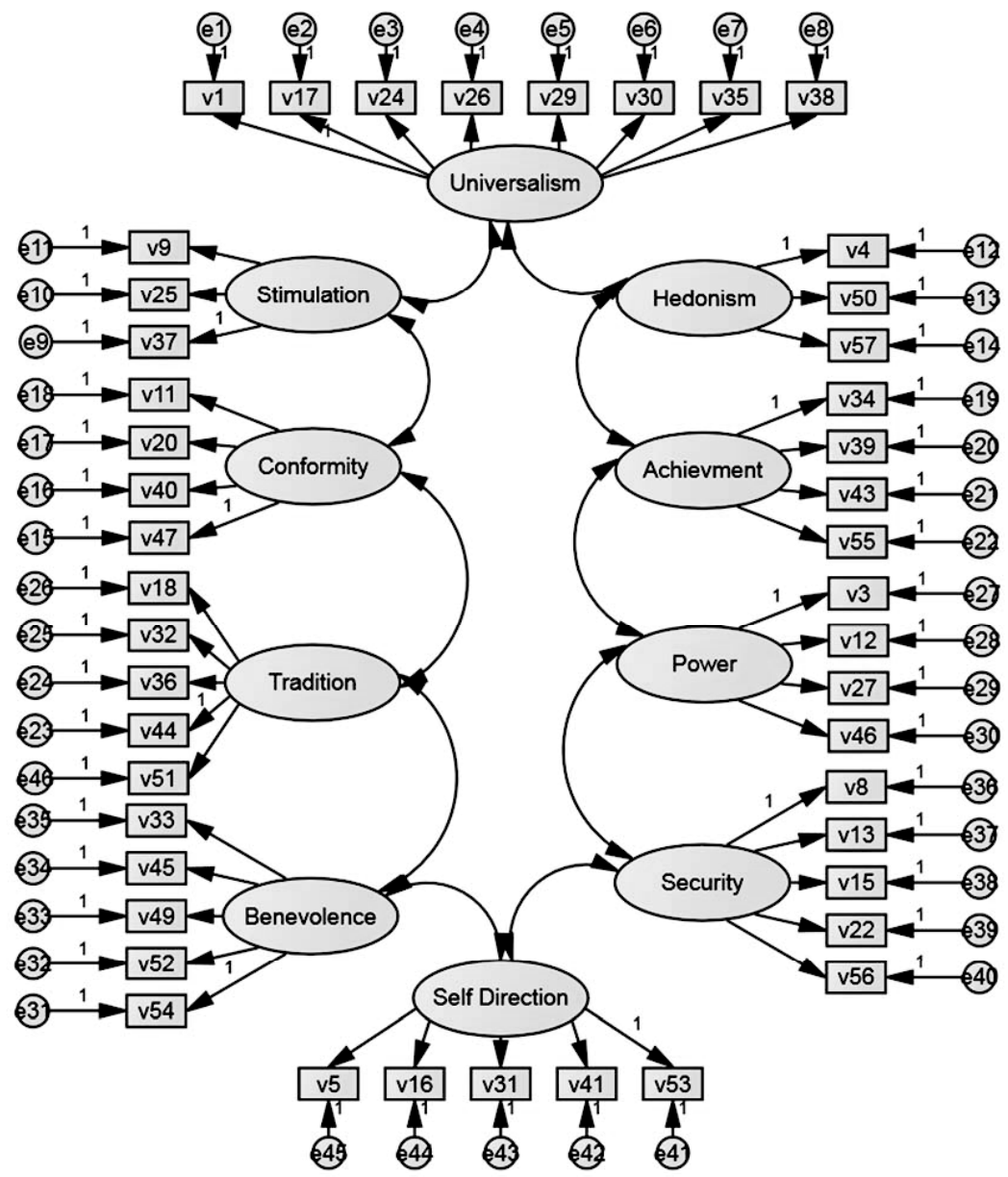

CFA are presented thus allowing a closer look at the specific reasons for the poor fit of the model. Here one can see in column 3, for each item, whether it has a low factor loading, a cross-loading, and/or an error correlation. Column 1 contains the information from the cognitive interviews and column 2 the information from the MDS analysis. Column 4 contains the information about whether the results of the cognitive interviews and CFA were consistent $(\mathrm{C})$, that is, whether both methods uncovered problems in an item, or were non-consistent (NC). We did not take the MDS results into account for column 4, as this method diagnosed a problem in one item only.

In Table 3, by comparing columns 1 and 3 one can see that the CFA identified even more problems than the cognitive interviews and the MDS. Furthermore, it 
is obvious that the technique of cognitive interviewing identified problems much more often than MDS. In quantitative terms, MDS identified a problem with one item whereas cognitive interviewing identified problems with 17 items. The one item identified by MDS was also identified by cognitive interviewing. Because the modification index used in CFA as a tool for the modification of models is a univariate test, it could have been possible that after a few modifications, the model would fit the data very well (Saris, Satorra \& Sörbom, 1987; Saris, Satorra $\&$ van der Veld, 2009). However, by introducing 4 error correlations and 20 crossloadings in a series of 24 sequential model modifications, the model fitted the data in a sufficient way. The fit indices of this revised model were CFI $=0.847$, chisquare $/ \mathrm{df}=3.89, \mathrm{SRMR}=0.047, \mathrm{RMSEA}=0.049$, and pclose $=0.805$. These 24 error correlations and cross-loadings were all significant. They are listed in column 3 of Table 3. In the fourth column we denote the items which were identified either both by cognitive interviews and CFA as problematic, or by one or the other method as problematic. It is important to note that for seven items, consistent results were found, whereas in 20 items, the results were inconsistent for the two methods. There may be several reasons for this. One reason might be the cut-off value of $50 \%$ chosen for the cognitive interviews. Another one may be the small sample size for the cognitive interviews although we have tried to use contrasting cases by varying age, gender, and education.

\section{DISCUSSION, LIMITATIONS AND OUTLOOK}

In the present contribution, a mixed methods approach combining qualitative (i.e., cognitive interviews) and quantitative (i.e., MDS and CFA) techniques was applied to the Russian-language version of the SVS to establish its validity (Adcock \& Collier, 2001, Meitinger 2017). We found that cognitive interviews identified many more problems of the survey questions than MDS. However, CFA identified even more problems than the cognitive interviews. Nonetheless, the results were not consistent for the two quantitative methods.

One limitation of our study has been that neither the English version nor the Russian version of the items were compared using the SQP Program Version 2 to check additionally for equivalence of meaning (Saris 2011). Furthermore the use of small samples in cognitive pretesting seems problematic, as the results may be too specific for the samples chosen. On-line cognitive pretest studies using probing techniques with larger samples $(\mathrm{N}>400)$ seems be a more valid approach (Behr \& Kaczmirek, \& Bandilla 2012).

Many survey items were problematic according to the results of the CFA because error correlations and cross-loadings and, to a lesser extent, low factor loadings were present. We might have reported more problems in the cognitive 
interviews if we had chosen a lower cut-off value for reporting problems, such as $30 \%$ instead of $50 \%$ of the cognitive pretest sample, which we applied and reported in Table 3. Since the study revealed difficulties in understanding instructions for the procedure, it is recommended to provide the respondents with a more detailed explanation of the task, thus avoiding potential difficulties in completing the survey. However, because the present instructions are already quite long, it is not recommended to add a new written clarification. It would be preferable to provide additional verbal explanations to the respondents at the time of the survey.

As a result of the qualitative evaluation of the SVS, we identified the survey items that did not cause any issues with understanding for the respondents, as well as the items which were found to be difficult to rate due to difficulty with their comprehension. Difficulties in understanding the values and their decodings were related to translation issues such as use of words rarely used in the language or of words differing substantially in meaning, for example, when the decoding of the value, originally designed to facilitate the understanding of the meaning of the value to the respondent, did not fit as a description of this item. In some cases there were issues with the name of the value itself and not only with its interpretation. These difficulties had an impact on the process of selecting response alternatives.

In addition, our study identified some problems of a more general nature related to the survey instructions. Specifically, participants encountered two major issues related to a) evaluating the real or the desired state of affairs (a person evaluates the way he/she wants to be or how things actually are in his/her life); and b) assessing oneself or other people (a person values being as such and values something particular, or it is important to him/her that other people be as such and value something particular). The current wording of the instructions does not cover these issues and, in the present version is stated as follows: "While giving answers to this survey, you should ask yourself: Which values are more important to me, as the fundamental principles of my life, and which are less important?"

The qualitative results are applicable for interpreting and understanding the quantitative data and vice versa (Brannen, 2009; Bryman, 2007), as was demonstrated by the MDS analysis but even more so by the CFA. It was possible to find explanations of the positions of individual items in the overall structure of values that were not typical of the original model by applying cognitive interviews.

The results show the importance of using cognitive interviewing for the analysis of survey instruments combined with CFA when sample sizes are large enough for CFA. Especially the error correlations of the indicators (items) and cross-loadings (invalid loadings) of the items on other factors revealed in CFA might be useful to validate findings from cognitive interviews (Latcheva, 2011). For the development of scales and the test of validity (Adcock \& Collier, 2001), the results demonstrated the usefulness of a mixed methods approach, as the cognitive interviews provided 
explanations as to why error correlations, low loadings, or cross-loadings arise. However, of the two quantitative methods, CFA seems to provide a more explicit diagnosis of these problems than MDS, which identified practically none of the problems of the items.

\section{REFERENCES}

Alemán, J., Woods, D. (2016) Value Orientations From the World Values Survey. How Comparable Are They Cross-Nationally? Comparative Political Studies. Vol 49, Issue 8, 2016.

Adcock, R. \& Collier, D. (2001). Measurement validity: A shared standard for qualitative and quantitative research. American Political Science Review, 95(3), 529-546. https://doi.org/10.1017/S0003055401003100

Beatty, P. C. \& Willis, G. B. (2007). Research synthesis: The practice of cognitive interviewing. Public Opinion Quarterly, 71(2), 287-311. https://doi.org/10.1093/ $\mathrm{poq} / \mathrm{nfm} 006$

Behr,D., Kaczmirek L., Bandilla W. \& Braun, M. (2012) Asking probing questions in web surveys: Which factors have an impact on the quality of the responses, Social Science Computer Review, 30(4), 487-498. https://doi.org/10.1177/0894439311435305

Beierlein, C., Davidov, E., Schmidt, P., Schwartz, S. H. \& Rammstedt, B. (2012). Testing the discriminant validity of Schwartz' Portrait Value Questionnaire items A replication and extension of Knoppen and Saris (2009). Survey Research Methods, 6(1), 25-36. https://doi.org/10.18148/srm/2012.v6i1.5092

Bilsky, W., Janik, M. \& Schwartz, S. H. (2011). The structural organization of human values: Evidence from three rounds of the European Social Survey. Journal of CrossCultural Psychology, 42(5), 759-776. https://doi.org/10.1177/0022022110362757

Blair, J., Conrad, F., Ackermann, A. C. \& Claxton G. (2006). The effect of sample size on cognitive interview findings. Paper presented at the American Association for Public Opinion Research Conference, Montreal, Canada, May 18-21. Retrieved from http://www.abtassociates.com/presentations/aapor06_sample_size_cognitive_ interviews.pdf

Boeije, H. \& Willis G. B. (2013). The Cognitive Interviewing Reporting Framework (CIRF). Towards the harmonization of cognitive testing reports. Methodology, 9(3), 87-95. https://doi.org/10.1027/1614-2241/a000075

Borg, I. \& Groenen P. (1997). Modern multidimensional scaling: Theory and applications. New York: Springer. https://doi.org/10.1007/978-1-4757-2711-1

Brannen, J. (2009). Prologue: Mixed methods for novice researchers: Reflections and themes. International Journal of Multiple Research Approaches, 3(1), 8-12. https:// doi.org/10.5172/mra.455.3.1.8

Braun, M., Behr, D. \& Kaczmarek, L. (2012). Assessing cross-national equivalence of measures of Xenophobia. Evidence from probing in web surveys. International Journal of Public Opinion Research, 25(3), 383-395. https://doi.org/10.1093/ijpor/ eds034

Brown, T. A. (2015). Confirmatory factor analysis for applied research. Second edition. London: Guilford Press. 
Bryman, A. (2007). Barriers to integrating quantitative and qualitative research. Journal of Mixed Methods Research, 1(1), 8-22. https://doi.org/10.1177/1558689806290531

Castro, F. G., Kellison, J. G., Boyd, S. J. \& Kopak, A. (2010). A methodology for conducting integrative mixed methods research and data analyses. Journal of Mixed Methods Research, 4(4), 342-360. https://doi.org/10.1177/1558689810382916

Cieciuch, J. \& Schwartz, S. H. (2012). The number of distinct basic values and their structure assessed by PVQ-40. Journal of Personality Assessment, 94(3), 321-328. https://doi.org/10.1080/00223891.2012.655817

Datler, G., Jagodzinski, W. \& Schmidt, P. (2013). Two theories on the test bench: Internal and external validity of the theories of Ronald Inglehart and Shalom Schwartz. Social Science Research, 42, 906-925. https://doi.org/10.1016/j. ssresearch.2012.12.009

Fontaine, R. J., Poortinga, Y. H., Delbeke, L. \& Schwartz, S. H. (2008). Structural equivalence of the values domain across cultures: Distinguishing sampling fluctuations from meaningful variation. Journal of Cross-Cultural Psychology, 39(4), 345-365. https://doi.org/10.1177/0022022108318112

Inglehart, R. (1997). Modernization and postmodernization: Cultural, economic, and political change in 43 societies. Princeton: Princeton University Press.

Hak, T., van der Veer, K., \& Jansen, H. (2008). The Three-Step Test-Interview (TSTI): An observation-based method for pretesting self-completion questionnaires. Survey Research Methods, 2(3), 143-150.

Harkness, J. \& van de Vijver F.J.R. \& Mohler P.(2003). Cross-Cultural Survey Methods. New York: J. Wiley.

Kluckhohn, C. \& Strodtbeck, F. (1961). Variations in value orientations. Evanston, IL: Row, Peterson.

Knoppen, D. \& Saris, W. E. (2009). Do we have to combine values in the Schwartz' human values scale? A comment on the Davidov studies. Survey Research Methods, 3(2), 91-103.

Latcheva, R. (2011). Cognitive interviewing and factor-analytic techniques: A mixed method approach to validity of survey items measuring national identity. Quality \& Quantity, 45(6), 1175-1199. https://doi.org/10.1007/s11135-009-9285-0

Lebedeva, N. M. (2001). Value-motivational personality structure in Russian culture. Psychological Journal, 22(3), 26-36.

Lebedeva, N. M., Tatarko, A. N. (2009) Kultura kak faktor obschestvennogo progressa. Moscow: Yustitsinform.

Lebedeva, N. M., Osipova, E. \& Cherkasova, L. (2013). Values and social capital as predictors of attitudes towards innovation. Research Working Paper WP 5/09, BRP Series: Sociology, M: NRU HSE.

Luyt, A. (2012). A framework for mixing methods in quantitative measurement development, validation and revision: A case study. Journal of Mixed Methods Research, 6(4), 294-316. https://doi.org/10.1177/1558689811427912

Meitinger,K.(2017) Necessary but Insufficient: Why Measurement Invariance Tests Need Online Probing as a complimentary Tool, Public Opinion Quarterly, 81(2), 447-472. https://doi.org/10.1093/poq/nfx009

Ozhegov, S. I. (2010). Dictionary of Russian language. Moscow: Onyx. 
Petros, S. G. (2012). Use of a mixed methods approach to investigate the support needs of older caregivers to family members affected by HIV and AIDS in South Africa. Journal of Mixed Methods Research, 6(4), 275-293. https://doi. org/10.1177/1558689811425915

Pruefer, P. (2011). Cognitive interviewing. A short overview. GESIS - Leibniz-Institute for the Social Sciences, Mannheim, Germany.

Robinson, S. \& Mendelson, A. L. (2012). A qualitative experiment: Research on mediated meaning construction using a hybrid approach. Journal of Mixed Methods Research, 6(4), 332-347. https://doi.org/10.1177/1558689812444789

Rogozin, D. M. (2002). Cognitive analysis of the Questionnaire Tool. Moscow: Institute of Public Opinion.

Rokeach, M. (1973). The nature of human values. New York: Free Press.

Różycka-Tran, J., Khanh Ha, T.T., Cieciuch, J., Schwartz, S. H. (2017). Universals and Specifics of the Structure and Hierarchy of Basic Human Values in Vietnam. Behavioral Research Vol. 42 p. 1-32. Health Psychology Report. 5(3) 193-204. https://doi.org/10.5114/hpr.2017.65857

Saris, W. E., Satorra, A. \& Sörbom, D. (1987). The detection and correction of specification errors in structural equation models. Sociological Methodology, 17, 105-129. https://doi.org/10.2307/271030

Saris, W. E., Satorra, A. \& van der Veld, W. (2009). Testing structural equation models or detection of misspecifications? Structural Equation Modeling, 16(4), 561-582. https://doi.org/10.1080/10705510903203433

Saris, W. E. (2011) Preface. Published in W. E. Saris, Oberski, D., Revilla, M., ZavalaRojas, D., Lilleoja, L., Gallhofer, I. and Gruner, T. The Development of the Program SQP 2.0 for the Prediction of the Quality of Survey Questions. RECSM.

Schmidt, P., Bamberg, S., Davidov, E., Hermann, J. \& Schwartz, S. H. (2007). Die Messung von Werten mit dem "Portraits Value Questionnaire" [The measurement of values with the "Portraits Value Questionnaire"]. Zeitschrift für Sozialpsychologie, 38(4), 261-275. https://doi.org/10.1024/0044-3514.38.4.261

Schüßler, A. \& Schmidt, P. (2008, September). Does cognitive interviewing matter? Testing the effects of cognitive methods on the data quality. Paper presented at the 7th International Conference on Social Science Methodology, Campus di Monte Sant' Angelo, Naples, Italy.

Schwartz, S. H. (1992). Universals in the content and structure of values: Theory and empirical tests in 20 countries. In M. Zanna (Ed.), Advances in experimental social psychology (Vol. 25, pp. 1-65). New York: Academic Press.

Schwartz, S. H. (1994). Are there universal aspects in the content and structure of values? Journal of Social Issues, 50, 19-45. https://doi.org/10.1111/j.1540-4560.1994. tb01196.X

Schwartz, S. H. (2005a). Basic human values: Their content and structure across countries. In A. Tamayo \& J. B. Porto (Eds.), Valores e comportamento nas organizações [Values and behavior in organizations] (pp. 21-55). Petrópolis, Brazil: Vozes.

Schwartz, S. H. (2005b). Robustness and fruitfulness of a theory of universals in individual human values. In A. Tamayo \& J. B. Porto (Eds.), Valores e comportamento 
nas organizações [Values and behavior in organizations] (pp. 56-95). Petrópolis, Brazil: Vozes.

Schwartz, S. H. (2006). Les Valeurs de Base de la Personne: Théorie, Mesures et Applications [Basic human values: Theory, measurement, and applications]. Revue Française de Sociologie, 42, 249-288. https://doi.org/10.3917/rfs.474.0929

Schwartz, S. H. (2014). National culture as value orientations: Consequences of value differences and cultural distance. In V. Ginsburgh \& D. Throsby (Eds.), Handbook of the economics of art and culture (Vol. 2, pp. 547-586). North Holland: Elsevier. https://doi.org/10.1016/B978-0-444-53776-8.00020-9

Schwartz, S. H. \& Bilsky, W. (1987). Toward a universal psychological structure of human values. Journal of Personality and Social Psychology, 53, 550-562. https:// doi.org/10.1037/0022-3514.53.3.550

Schwartz, S. H. \& Boehnke, K. (2004). Evaluating the structure of human values with confirmatory factor analysis. Journal of Research in Personality, 38, 230-255. https://doi.org/10.1016/S0092-6566(03)00069-2

Schwartz, S. H., Cieciuch, J., Vecchione, M., Davidov, E., Fischer, R., Beierlein, C., ... Konty, M. (2012). Refining the theory of basic individual values. Journal of Personality and Social Psychology, 103(4), 663-668. https://doi.org/10.1037/ a0029393

Smith, T. W. (2011). Refining the Total Survey Error Perspective. International Journal of Public Opinion Research, 23(4): 464-484. https://doi.org/10.1093/ijpor/edq052

Tourangeau, R. (1984). Cognitive sciences and survey methods. In T. Jabine, M. Straf, J. Tanur \& R. Tourangeau (Eds.), Cognitive aspects of survey methodology: Building a bridge between disciplines (pp. 73-100). Washington, DC: National Academy Press.

Willis, G. B. (2005). Cognitive interviewing. A tool for improving questionnaire design. Thousand Oaks, CA: Sage Publications. https://doi.org/10.4135/9781412983655

Wolf, C., Joye, Ch. D., Smith, T.W., Fu, Y. (2016). The SAGE Handbook of Survey Methodology. pp. 503-524. Thousand Oaks, CA: Sage. https://doi. org/10.4135/9781473957893 


\section{APPENDIX}

Illustrative Cognitive Interview Data of the Difficulties in Understanding the Values "Reciprocation of Favors" and "Broadminded"

Example 1. "Reciprocation of favors (avoidance of indebtedness)": "This word makes me shudder... Not "avoidance of indebtedness" but... if we speak of desire to help people... Better would be "mutual assistance." Because "reciprocation of favors" and "avoidance of indebtedness" sounds as something...sounds formal. It is unpleasant, because it underlines "facade" of relationships. It seems as if it isn't important what a person really feels, but it is appropriate for him to avoid indebtedness and it is proper to pay back any debts. And it is an unpleasant thing. And for me this is right about "reciprocation of favors." But "mutual assistance"-a sincere desire to help other people and also the capability to accept help from others";

Example 2. "Broadminded (tolerant of differentideas and beliefs)": "Broadmindedit is the possibility to look at...um-um-um...at some events from other points of view. And it is, maybe, about much wider knowledge in different fields. But the explanation in parentheses-it is simply about a tolerant person, not about broadmindedness." 